Irineu COTRIM JUNIOR ${ }^{1}$

Fernanda Branco Lyra

PORTO $^{1}$

Adriana MUNIZ1

Aníbal de Sant'Anna

MORETTI ${ }^{1}$

Sidney Franklin Araújo dos SANTOS ${ }^{1}$

Simone Maria Massami

Kitamura MARTINS

Correspondência para:

ANÍBAL DE SANT'ANNA MORETTI

Departamento de Nutrição e Produção Animal

Faculdade de Medicina Veterinária e Zootecnia

Universidade de São Paulo

Rua Duque de Caxias Norte, 225

13.630-000 - Pirassununga SP

adsamore@usp.br

Recebido para publicação: 11/02/2004 Aprovado para publicação: 01/06/2005

\title{
Efeito da metoclopramida sobre a produção leiteira de porcas no puerpério e o ganho de peso dos leitões
}

1 - Laboratório de Pesquisa em Suínos do Departamento de Nutrição e produção Animal da Faculdade de Medicina Veterinária Zootecnia da Universidade de São Paulo, Pirassununga - SP

\section{Resumo}

A metoclopramida vem sendo utilizada em mulheres como terapia para incremento lactogênico não havendo na literatura informações sobre a utilização desta droga em suínos. O estudo objetivou, avaliar os efeitos da metoclopramida na produção de leite e desempenho da leitegada. Foram utilizadas 12 fêmeas suínas, as quais foram homogeneizadas de acordo com a ordem de parto. A padronização das leitegadas foi estabelecida em 10 leitões por fêmea, totalizando 120 leitões. O delineamento experimental foi inteiramente casualizado caracterizado por medidas repetidas no tempo, sendo definidos dois tratamentos com seis respectivos cada. No tratamento controle (T1) foi feita a aplicação intra-muscular de soro fisiológico nos três primeiros dias pós-parto e no tratamento 2 (T2) foi aplicado metoclopramida. A metoclopramida influenciou significativamente $(\mathrm{p}<0,05)$ na produção de leite, nos três primeiros dias, havendo maior produção em relação ao controle. Não houve diferenças significativas quanto ao ganho de peso dos leitões nas faixas etárias avaliadas, havendo diferença significativa $(\mathrm{p}<0,05)$ no peso dos leitões no $7^{\circ}$ dia de vida. Destacou-se no estudo maior homogeneidade e menor dispersão da leitegada proveniente das fêmeas tratadas com metoclopramida, evidenciados pelos valores máximos e mínimos observados aos 21 dias de idade $(\mathrm{p}<0,06)$. Concluiu-se que a metoclopramida provocou aumento do aporte lactacional em fêmeas suínas, nos três primeiros dias de lactação, cujo efeito traduziu-se na melhor homogeneidade da leitegada.

\section{Introdução}

As inovações científicas no meio suinícola encontram sua aplicação a médio ou longo prazo. No rol das inovações em curto prazo, as melhorias na produção de leite das fêmeas e seu reflexo, principalmente nas primeiras semanas de vida dos leitões, devem merecer atenção especial, pois influenciam no desempenho e na viabilidade futura.

No ciclo reprodutivo da porca, a lactação exerce papel essencial pelo oferecimento de colostro e leite para a sobrevivência dos leitões neonatos ${ }^{1}$. As
Palavras-chave: Lactação. Leitões. Metoclopramida. Porcas. Prolactina. propriedades do colostro e do leite são essenciais para fornecer ao neonato aporte nutricional que maximiza o desempenho na expressão de seu potencial genético.

A maior ingestão de colostro nas primeiras horas após o nascimento ${ }^{2}$ e durante as três primeiras mamadas, representa $25 \%$ da quantidade total de colostro ingerida durante o primeiro dia, conferindo condição de amadurecimento fisiológico e metabólico primordiais a precocidade no desenvolvimento.

O colostro supre o leitão com fon-tes de nutrientes que previnem o surgimen-to da hipoglicemia além de fornecer imunoglobulinas essenciais importantes para a 
termorregulação e resistência às doenças. A suficiente produção de leite e de colostro contribui para a baixa taxa de mortalidade e maior viabilidade, influindo sobremaneira na homogeneidade da leitegada. Menor ingestão de colostro e leite leva a maiores riscos de esmagamento ou mesmo a ocorrência da hipoglicemia neonatal, principais causas de mortalidade dos leitões ${ }^{4}$. O efeito da ingestão deficiente de colostro resulta em rápido aumento na glicose e galactose plasmática, assim como no expressivo aumento da atividade da lactase nos enterócitos do intestino delgado ${ }^{5}$.

A prolactina é um hormônio essencial para a lactogênese dos mamíferos incluindo o suíno ${ }^{6}$. A dramática redução de progesterona no pré-parto promove o desencadeamento da lactação, e pela estimulação da teta, por contato manual ou sucção dos leitões, inicia-se a liberação de prolactina da glândula pituitária anterior e ocitocina da pituitária posterior. A prolactina estimula a produção e secreção de leite, enquanto que a ocitocina, está envolvida com contração das células mioepiteliais dentro do úbere, resultando na descida do leite. A prolactina regula ainda o volume de leite produzido, e sua secreção é inibida pela dopamina liberada dos neurônios secretórios localizados no hipotálamo médio basal ${ }^{7}$. A dopamina liberada destes neurônios é transportada pela veia porta hipofisária para a glândula pituitária, onde interage com receptores D2 de dopamina, levando a uma depressão da secreção de prolactina ${ }^{8}$. A metoclo pramida, como antagonista da dopamina, tem demonstrado induzir com sucesso a lactação em algumas espécies.

Em adição ao aumento de prolactina em bovinos ${ }^{10}$, a administração de metoclopramida também estimulou a secreção de prolactina em ratos ${ }^{11}$, humanos ${ }^{12}$, cavalos $^{13}$, e ovelhas prenhes ${ }^{14}$.

Uma vez que sistemas dopaminérgicos centrais estão relacionados com diversos comportamentos e com o controle neuroendócrino da prolactina e de outros hormônios, o presente estudo propõe avaliar os efeitos de um bloqueador de receptores de dopamina, do tipo D2 adenohipofisário, a metoclopramida, sobre as alterações lactogênicas no período pós-parto.

Objetivou-se verificar a ação da droga nos três primeiros dias puerperais da porca, analisando seus efeitos na produção de leite, ganho de peso, peso e homogeneidade da leitegada, durante o aleitamento.

\section{Materiais e Métodos}

O experimento foi realizado em um sistema intensivo de criação de suínos, no sítio Santa Maria, no município de Itobí SP, sendo utilizadas 12 fêmeas F1, híbridas, Yokshire x Landrace, homogêneas quanto ao escore corporal, número de partos, linhagem e número de glândulas funcionais. Os tratamentos utilizados foram: tratamento 1 (T1), sem aplicação de metoclopramida e tratamento 2 (T2) com aplicação de metoclopramida. Na fase de gestação, as fêmeas foram alojadas em instalações individuais, sendo transferidas para as gaiolas de parição na maternidade, aos 110 dias de gestação. O parto foi induzido utilizando-se Lutalise $^{\circledR}$ (PGF2 $\mu$ ), e esse manejo, normalmente realizado na granja, propiciou a sincronização e homogeneização das fêmeas na ocasião do parto. A alimentação até o pré-parto constou da ração de gestação oferecida na quantia de $2,0 \mathrm{Kg} /$ dia. A ração de lactação foi colocada à disposição das fêmeas em quantidades crescentes de 2,0, 3,0 e 4,0 Kg do primeiro ao terceiro dia de lactação, sendo posteriormente oferecido à vontade. $\mathrm{O}$ arraçoamento foi fornecido em dois períodos, pela manhã e à tarde. Os animais receberam as mesmas quantidades de alimento; a água oferecida à vontade.

$\mathrm{O}$ dia 0 foi determinado como sendo o dia do parto. Neste, ao final da tarde, quando todas as fêmeas haviam parido, os leitões foram distribuídos de forma homogênea, caracterizando 10 leitões por porca, observando-se peso e conformação similares, o que totalizou 120 leitões.

No T2, a metoclopramida (MC) foi 
aplicada na musculatura cervical lateral, na dosagem de $10 \mathrm{ml}$, equivalente a $50 \mathrm{mg}$ do produto por porca em cada aplicação, totalizando $150 \mathrm{mg}$ diárias em um total de 450 mg correspondentes aos três primeiros dias experimentais. Empregou-se dose terapêutica ${ }^{15}$. As injeções foram administradas em intervalos de oito horas, durante os três primeiros dias de tratamento, totalizando nove aplicações. No T1 as fêmeas receberam solução de cloreto de sódio a $0,9 \%(\mathrm{NaCl})$ na mesma via que $\mathrm{T} 2$ e idêntico procedimento.

Aos sétimo, $14^{\circ}, 21^{\circ}$ dias de vida dos leitões, procedeu-se à pesagem individual dos animais, visando-se avaliar o ganho de peso no período.

A técnica pelo método "pesa-mamapesa" foi utilizada nos três primeiros dias pós-parto ${ }^{16}$. A seqüência de procedimentos metodológicos adotados para aferição dos parâmetros desejados foi: 1- Os leitões eram colocados para mamar em intervalos de uma hora, seguindo variação entre mamadas de 55 a 65 minutos. 2- Os leitões eram despertados no escamoteador e para evitar o erro na estimativa da produção de leite, devido às excreções entre as pesagens, os mesmos eram colocados em um piso frio revestido por um pano úmido, sempre antes da pesagem que precedia a mamada, por alguns minutos. Esta operação, normalmente obtinha sucesso, no encorajamento dos leitões para que urinassem e defecassem antes dos procedimentos de pesagens. Os leitões foram colocados junto à porca, e observados quanto eventuais fatos de urinar ou defecar. Neste caso pesava-se novamente. 3- Foram avaliadas oito mamadas por dia, iniciando-se no período da manhã. As duas primeiras mamadas, eram consideradas como de adaptação, as quais não foram utilizadas nos cálculos da produção de leite. Para o cálculo, utilizaramse as seis mamadas seguintes. Multiplicavase o valor das seis mamadas por quatro, a fim de se obter a estimativa da produção de leite diária. 4- Os leitões foram pesados, individualmente, antes e depois das mamadas. O tempo de pesagem foi de aproximadamente 4 minutos, e toda operação completou-se em aproximadamente 12 minutos. 5- A produção de leite foi aferida mediante ingestão individual, de cada leitão, em cada mamada. 6- Utilizou-se balança com precisão de $5 \mathrm{~g}$, Assumindo-se, na metodologia experimental, compromisso de espera entre a colocação dos leitões na balança e a estabilização da mesma, devido à movimentação dos mesmos durante a pesagem. 7- Foram realizadas oito avaliações da produção diária/porca. Desse número subtraiu-se 2 (que foram as duas primeiras), e em seguida foi multiplicado por seis, para que tivéssemos a produção em 24 horas. As avaliações foram realizadas nos três primeiros dias após o parto, como foi referido anteriormente, sendo que o tempo zero (0) do período experimental, coincidente com a aplicação da droga. Nesse momento providenciou-se a homogeneização da leitegada para 10 leitões por fêmea, sendo esta técnica possível dada à sincronização dos partos pela aplicação da droga indutora.

Este procedimento iniciava-se às sete horas da manhã e repetia-se as oito, nove, dez, onze, doze, treze, quatorze e às quinze horas do dia.

Os dados foram submetidos a análise estatística, utilizando-se o PROC MIXED para avaliação da produção de leite e ganho de peso. Para as análises de peso dos leitões utilizou-se o PROC GLM ${ }^{17}$. O delineamento experimental em parcelas subdivididas com medidas repetidas no tempo para análise da homogeneidade da leitegada empregou-se o teste de Bartlett.

\section{Resultados e Discussão}

Nos três primeiros dias de administração da droga, os resultados identificaram diferença significativa $(\mathrm{P}<0,05)$ na produção de leite (Tabela 1) indicando valores superiores $(4,442 \pm 1,376 \mathrm{kgs}$ vs. 3,329 $\pm 1,152$ kgs, respectivamente) do tratamento com metoclopramida (T2) em comparação ao tratamento sem metoclopramida (T1).

$\mathrm{Na}$ Figura 1 nota-se na curva de lactação 
Tabela 1 - Médias, desvios padrão da produção de leite dos tratamentos 1 e 2 nos três primeiros dias de lactação, isoladamente e no total. Pirassununga, 2003

\begin{tabular}{ccccc}
\hline Prod. & Dia 1 & Dia 2 & Dia 3 & Total \\
\hline Trat. 1 & 2,720 & 3,770 & 4,013 & $3,329^{\mathrm{a}} \pm 1,151$ \\
Trat. 2 & 3,347 & 4,740 & 5,563 & $4,442^{\mathrm{b}} \pm 1,377$ \\
\hline
\end{tabular}

As observações sobrescritas com letras diferentes (a e b) são estaticamente diferentes $(\mathrm{P}<0,05)$.

nítida diferença a partir do segundo dia no tratamento 2, com evoluir crescente, enquanto no tratamento 1 evidencia-se ligeira estabilização.

Destaca-se que houve maior aporte de leite das fêmeas que receberam a droga nos três dias avaliados. Valores semelhantes quanto ao consumo de colostro alcançam cifras de 315 a $340 \mathrm{~g} / \mathrm{Kg}$ de peso vivo ${ }^{19}$. Os leitões que mais se aproximaram destes valores foram justamente os do tratamento 2 (312g/ $\mathrm{kg}$ de peso vivo), diferente do tratamento $1(235 \mathrm{~g} / \mathrm{kg}$ de peso vivo por dia).

A produção de leite por leitão em cada mamada desde o nascimento até o terceiro dia foi de 13,88g para o T1 e de 18,25 para o T2, observando-se superioridade do T2, assemelhando-se com valores estabelecidos para a produção de leite no sétimo dia ${ }^{18}$. A diferença de $5 \mathrm{~g}$ entre os tratamentos até o $3^{\circ}$ dia e comparável ao de $7 \mathrm{~g}$ até o sétimo dia $^{18}$ denotando pela semelhança, a ação significativa da droga na produção de leite.

No ganho de peso dos leitões do nascimento ao sétimo dia, do sétimo ao $14^{\circ}$ dia, do $14^{\circ}$ ao $21^{\circ}$ dias pós-parto (Tabela 2), os valores médios de 1,619 $\pm 0,584$ e de
$1,713 \pm 0,471 \mathrm{~kg}$ para o T1 e T2, respectivamente, não revelaram diferença significativa $(\mathrm{P}>0,05)$, apesar da diferença numérica identificar valor superior do T2 em relação ao T1. A média em ganho de peso (Figura 2), obtida até o desmame de 231 $\mathrm{g} /$ dia para a leitegada do T1 e de $245 \mathrm{~g} /$ dia para o T2, assemelham-se aos estudos que avaliaram o intervalo entre mamadas sobre a produção de leite ${ }^{20}$, sendo superiores a estudos realizados em condições ambientais idênticas de variação da temperatura ${ }^{21}$.

As referidas observações partem de estudos que na realidade não empregaram a droga, mas oferecem valores comparativos numéricos de produção de leite empregando-se técnicas semelhantes.

Em relação ao peso nos dias um, dois, três, 14 e 21 pós-parto (Tabela 3) os valores não mostraram diferenças significativas, apesar de serem destacados valores numéricos indicando superioridade dos leitões provenientes das fêmeas que receberam metoclopramida (T2) em comparação aos leitões do T1. Aos sete dias de idade identificou-se diferença significativa $(\mathrm{P}<0,05)$ entre os tratamentos, com valor

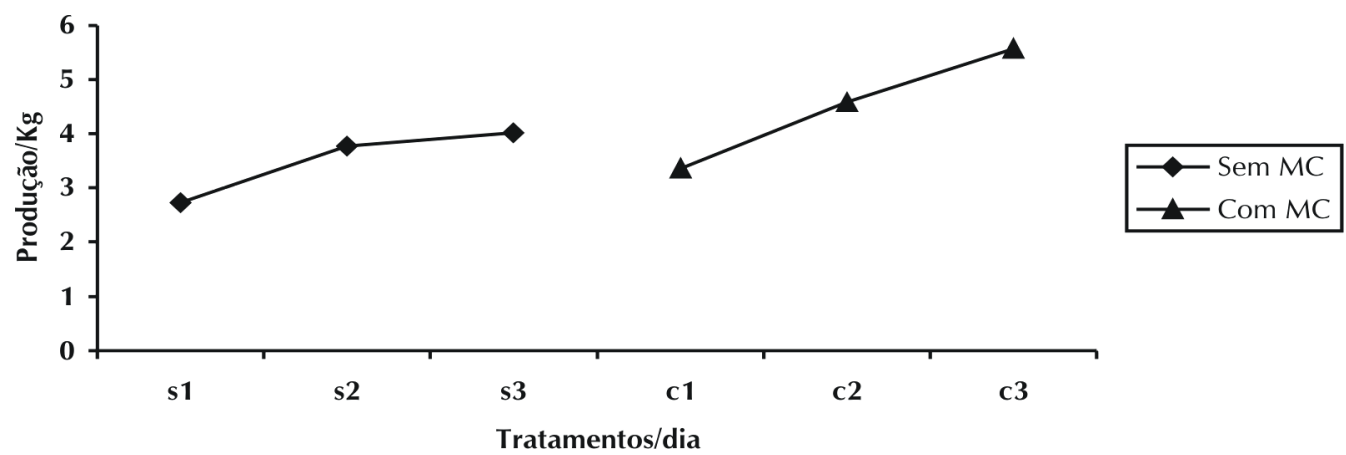

Figura 1 - Curva de produção de leite das fêmeas que receberam metoclopramida (Sem MC) e das que não receberam (Com MC) nos três primeiros dias pós-parto 
superior do T2 em relação ao T1.

Conforme destacado na Figura 3, esse resultado revela o efeito da droga no aumento da produção de leite e conseqüente peso dos leitões logo após a aplicação da droga. Nas idades subseqüentes e principalmente no desmame, a variabilidade no peso dos leitões tem se mostrado elevada e devido à quantidade de leite produzido pela porca e ingerido pelos leitões. Assim, fatores

Tabela 2 - Médias e desvios padrão do ganho de peso (GP) dos leitões do nascimento ao sétimo dia, do sétimo ao $14^{\circ}$ dia, do $14^{\circ}$ ao $21^{\circ}$ dias pósparto e no total para os três intervalos, nos tratamentos 1 e 2. Pirassununga, 2003

\begin{tabular}{lllll}
\hline Ganho de & Dia $0-7$ & Dia $7-14$ & Dia $14-21$ & Total \\
\hline Trat. 1 & $1,058 \pm 0,395$ & $1,920 \pm 0,492$ & $1,879 \pm 0, .438$ & $1,612 \pm 0,584$ \\
Trat. 2 & $1,255 \pm 0,294$ & $1,982 \pm 0,494$ & $1,901 \pm 0,208$ & $1,713 \pm 0,472$ \\
\hline
\end{tabular}

Tabela 3 - Médias, desvios padrão e valores mínimos e máximos dos pesos dos leitões, no primeiro, segundo, terceiro, sétimo, $14^{\circ}$, e $21^{\circ}$ dia de lactação, nos tratamentos 1 e 2. Pirassununga, 2003

\begin{tabular}{|c|c|c|c|c|}
\hline & \multicolumn{4}{|c|}{ TRATAMENTOS } \\
\hline & \multicolumn{2}{|c|}{ Tratamento 1} & \multicolumn{2}{|c|}{ Tratamento 2} \\
\hline & \multicolumn{2}{|c|}{$1.766 \pm 0.22$} & \multicolumn{2}{|c|}{$1.778 \pm 0.18$} \\
\hline \multirow[t]{2}{*}{ Dia 1} & 1.140 & 2.310 & 1.490 & 2.325 \\
\hline & \multicolumn{2}{|c|}{$1.888 \pm 0.23$} & \multicolumn{2}{|c|}{$1.890 \pm 0.19$} \\
\hline \multirow[t]{2}{*}{ Dia 2} & 1.475 & 2.460 & 1.585 & 2.355 \\
\hline & \multicolumn{2}{|c|}{$2.078 \pm 0.25$} & \multicolumn{2}{|c|}{$2.088 \pm 0.19$} \\
\hline \multirow[t]{2}{*}{ Dia 3} & 1.660 & 2.635 & 1.680 & 2.560 \\
\hline & \multicolumn{2}{|c|}{$2.819^{\mathrm{a}} \pm 0.50$} & \multicolumn{2}{|c|}{$3.021^{\mathrm{b}} \pm 0.40$} \\
\hline \multirow[t]{2}{*}{ Dia 7} & 1.770 & 3.845 & 2.040 & 4.030 \\
\hline & \multicolumn{2}{|c|}{$4.737 \pm 1.04$} & \multicolumn{2}{|c|}{$5.003 \pm 0.96$} \\
\hline \multirow[t]{2}{*}{ Dia 14} & 2.405 & 6.435 & 2.255 & 6.755 \\
\hline & \multicolumn{2}{|c|}{$6.616 \pm 1.51$} & \multicolumn{2}{|c|}{$6.831 \pm 1.18$} \\
\hline Dia 21 & 2.755 & & 4.060 & \\
\hline
\end{tabular}

* As observações sobrescritas com letras diferentes (a e b) são estaticamente diferentes $(\mathrm{P}<0,05)$

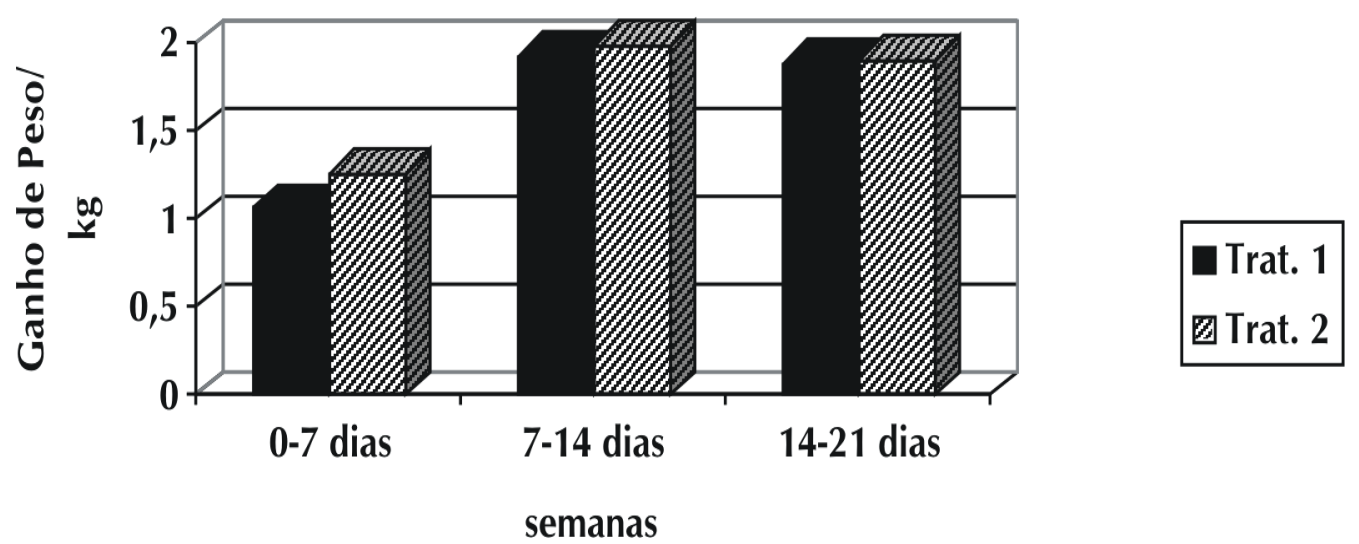

Figura 2 - Média de ganho de peso dos leitões, em $\mathrm{kg}$, dos tratamentos 1 e 2, do nascimento ao sétimo dia; do sétimo ao $14^{\circ}$ dia e do $14^{\circ}$ ao $21^{\circ}$ de vida 


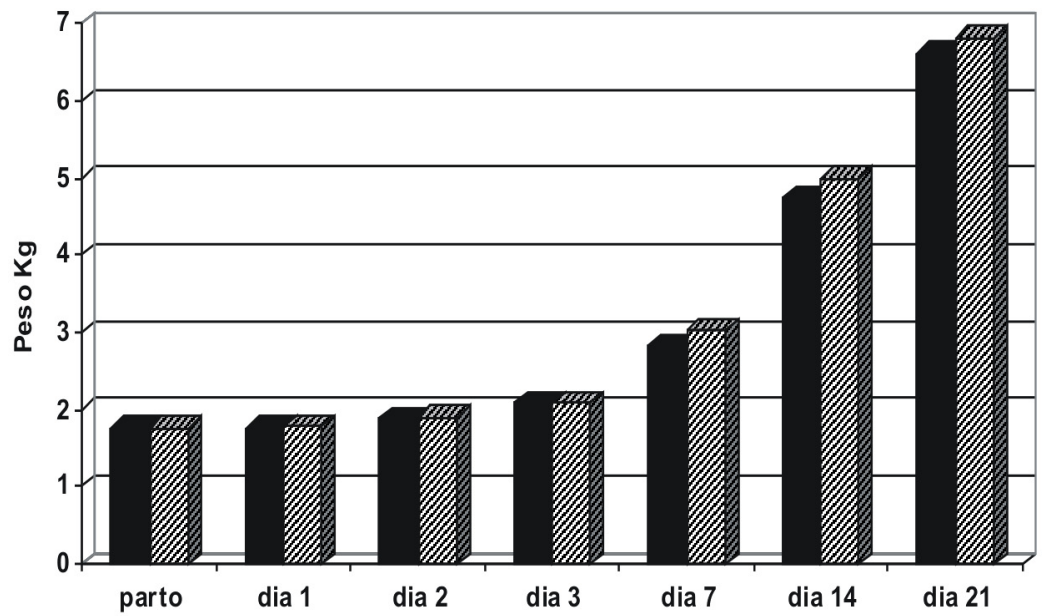

Figura 3 - Peso médio dos leitões, em kg, nos tratamentos 1 e 2, no momento do parto, ao primeiro (dia 1), segundo (dia 2), terceiro (dia 3), sétimo (dia 7), $14^{\circ}$ dia e $21^{\circ}$ dia de vida

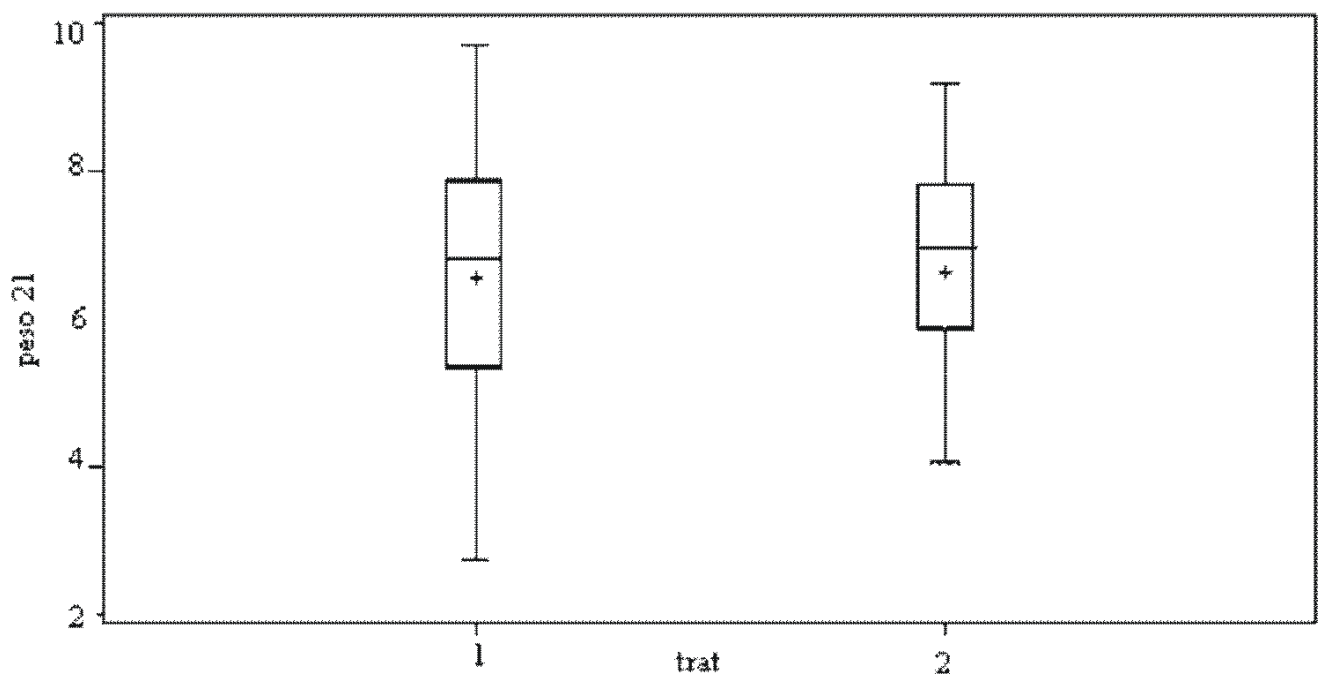

Figura 4 - Gráfico da dispersão dos pesos entre os leitões nos tratamentos 1 e 2, ao desmame (21 dias de idade). No retângulo, estão contidos $50 \%$ dos dados. O sinal " + " representa a média e a linha no retângulo logo acima do sinal " + " representa a mediana. Os pesos mínimos e máximos estão representados pelas extremidades das linhas, abaixo e acima do retângulo

que interferem na produção de leite da porca devem também influenciar no peso da leitegada $\mathrm{a}^{22}$. Os valores relativos aos pesos dos leitões aos sete, 14, 21 dias, mostram-se inferiores comparativamente aos verificados no presente modelo experimental ${ }^{16}$ mas que se encontram dentro da faixa de produção esperada na média das linhagens.
Nos pesos mínimos e máximos apresentados na Tabela 3 e ressaltada a homogeneidade da leitegada, através do grau de dispersão, observando-se diferenças marcantes entre os valores nos tratamentos, particularmente aos 21 dias. Destacou-se maior homogeneidade e menor dispersão dos valores no T2, em comparação ao T1, 
representados graficamente com destaque na Figura 4. A referida figura representa pelo retângulo nos quais inserem-se $50 \%$ dos dados, o restante dos dados caracterizam as linhas, cujos extremos identificam os valores máximos e mínimos. Portanto, o efeito do T2, além de sua significância no peso aos sete dias, nas demais idades, incluindo ao desmame (21 dias) manifestou-se determinando valores em peso superiores numericamente em comparação ao T1, aproximando-se da significância de 5\%. Desta maneira, e, pela análise de dispersão aos 21 dias, verificou-se homogeneidade diferenciada da leitegada, mostrada na Figura 4 , sendo esse fato importante nos sistemas de produção, pois destaca uma condição básica essencial de desempenho dos leitões nas idades subseqüentes. A relação estabelecida encontra de certa forma fundamento na imaturidade fisiológica e metabólica que envolvem os leitões nesses três primeiros dias de vida.

O teste de Bartelett empregado revelou diferença significativa $(\mathrm{P}=0,06)$ entre os tratamentos aos 21 dias, demonstrando maior homogeneidade da leitegada do T2 em relação ao T1, o que caracterizou haver efeito positivo pelo maior aporte nutricional do T2 nos dias avaliados. Tal resultado relaciona-se com a ingestão de colostro ${ }^{5}$, cujos efeitos no desenvolvimento do leitão são apreciáveis, resultando entre outros fatores como possível aumento na glicose e galactose plasmática, assim como em expressivo incremento da atividade da lactase nos enterócitos do intestino delgado, atuando assim, como os ácidos graxos presentes no leite, de maneira importante na correção da hipoglicemia ${ }^{11}$. Dessa maneira, o colostro é um substrato essencial para o leitão, que é altamente susceptível a hipoglicemia por conseqüência de gliconeogênese hepática deficiente $^{23}$. Assim, são marcantes os efeitos da metoclopramida na maior produção de leite, significando maior aporte de nutrientes e atuando positivamente na maturidade fisiológica dos leitões, relacionados a gliconeogênese, a imunidade, a termorregulação e a outros fatores que venham a influenciar no desempenho futuro dos leitões. Ainda em relação à gliconeogênese ${ }^{24}$, a normoglicemia dos leitões implica em aleitamento ad libitum e que a gliconeogênese é severamente deficiente, a menos que a mamada seja completamente concedida. A suplementação de colostro menos competitiva nos neonatos, ocasionaria em melhora na gliconeogênese. Desta maneira, justifica-se a homogeneidade superior encontrada na leitegada do T2, pois a influencia da metoclopramida na disponibilidade de nutrientes foi significativamente maior, através da medida indireta da produção de leite $(\mathrm{P}<0,05)$.

Este estudo, pelo seu ineditismo, abre campo para novas pesquisas com antagonistas da dopamina, visando avaliar os efeitos na produção de leite e reflexos no neonato. Aplicouse no modelo, a dose terapêutica de efeito antiemético por três dias e três vezes ao dia, talvez uma única dose num único dia fosse mais indicado. Em mulheres a dose única já foi utilizada com respostas satisfatórias na elevação dos níveis séricos de prolactina, objetivando incremento da lactação.

Novos estudos, portanto, precisam ser desenvolvidos visando além desses aspectos, os efeitos relevantes direcionados para a maior homogeneidade da leitegada e com isso, levando a maior viabilidade e conseqüentemente menores perdas de leitões nos períodos mais críticos e principalmente na primeira semana. Os efeitos posteriores seriam na creche e final da engorda, havendo da mesma maneira, menor variabilidade e conseqüente homogeneidade das carcaças, com maiores lucros para o criador.

\section{Conclusões}

De acordo com os resultados obtidos neste trabalho, podemos concluir que:

1. A metoclopramida, aplicado em fêmeas suínas nos três primeiros dias pós-parto, na dosagem de $50 \mathrm{mg}$ administrado por via intramuscular, com intervalos de oito horas, é capaz de aumentar a produção de leite em até $25,06 \%$

2. Leitegadas de fêmeas que receberam metoclopramida, conforme esquema terapêutico indicado apresentaram-se mais homogêneas ao desmame. 


\title{
Effect of metoclopramide on sow's milk production and the performance of piglets
}

\begin{abstract}
Metoclopramide has been used in humans as a therapy to increase milk production. There is no information available about this drug in swine for the same purpose. The objective of the study was to evaluate the effects of metoclopramide on lactation of swine females and litter development. For this reason 12 females were used in this study. They were assigned in two groups (T1 and T2) and were druginduced farrowing. T1 females received saline solution during three days after farrowing and T2 group received metoclopramide. The experimental period lasted 42 days starting from the administration of the drug. Metoclopramide significantly $(p<0,05)$ affected milk production at the first three days compared to the control females. In the study we found greater homogeneity and smaller dispersion of litter weight from females treated with metoclopramida, based upon piglet weight at 21 days of age. In conclusion metoclopramide induced higher milk production in swine on the first tree days of lactation and affected litter homogeneity.
\end{abstract}

\section{Referências}

1 HARTMANN, P. E.; HOLMES, M. A. Sow lactation. In: BARNETT, J. L.; HENNESSY, D. P. (Ed.). Physiological strategies in lactation. London: Academic Press, 1989. p. 301-326.

2 FRASER, D.; RUSHEEN, J. Colostrum intake by newborn piglets. Canadian Journal of Animal Science, v. 72 , p. 1-13, 1992.

3 LE DIVIDICH, J.; Et al. Effect of colostral fat on fat deposition and plasma metabolites in newborn pig. Journal of Animal Science, v. 69, p. 2480-2488, 1991.

4 EDWARDS, S. A.; Et al. Na analysis of the causes of piglets mortality in a breeding herd kept outdoors. Veterinary Records, v. 135, p. 324-327, 1994.

5 LE DIVIDICH, J.; NOBLET, J. Effect of colostrum intake on metabolic rate and plasma glucose in the neonatal pig in relation to environmental temperature. Biology Neonate, v. 46, n. 2, p. 98-104, 1984.

6 TUCKER, H. A. Endocrine and neural control of the mammary gland. In: LARSON, B. L. (Ed.). Lactation. Ames: The lowa State Universty Press, 1985. p. 39-79.

7 MOORE, K. E. Interaction between prolactin and dopaminergic neurons. Biology of Reproduction, $v$. 36, p. 47-58, 1987.

8 MELTZER, H. Y.; Et al. Comparison of the effects of substituted benzamides and standard neuroleptics on the binding of $\mathrm{H}$-spiroperidol in the rat pituitary and striatum with in vivo effects of rat prolactin secretion. Life Science, v. 36, p. 47-58, 1979.

9 EHRENKRANZ, R. A. Metoclopramide effect on faltering milk production by mothers of premature infants. Pediatrics, v. 78, p. 614-620, 1986.

10 LIPHAM, L. B.; THOMPSON, F. N.; STUEDEMANN, J. A. Effects of metoclopramide and quipazine on serum prolactin concentrations in steers. Journal of Veterinary Pharmacology and Therapeutics, v. 15, p. 78-84, 1992.

11 FERRE, P.; Et al. Interactions in vivo between oxidation of non-etherified fatty acids and gluconeogenesis in the newborn rat. Biochemical Journal, v. 182, n. 2, p. 593-598, 1979.

12 HEALY, D. L.; Et al. Prolactin in human milk: correlation with galactose, total protein, and lactalbumin levels. American Journal of Physiology, v. 238, p. 283, 1980.

13 JOHNSON, A. L.; BECKER, S. E. Effects of physiologic and pharmacologic agents on serum prolactin concentrations in the nonpregnant mare. Journal of Animal Science, v. 65, p. 1292-1297, 1987.

14 WUQING, O.; QIUFANG, W.; SHOUCHANG Y. Effects of metoclopramide on the milkability of milk goats. Acta Universitatis Agriculturalis Boreali Occidentalis. v. 21, p. 104-107, 1993.

15 SZELENYI, I.; HEROLD, H.; GOTHERT, M. Emesis induced in domestic pigs: a new experimental tool for detection of antiemetic drugs and for evaluation of emetogenic potential of new anticancer agents. Journal of Pharmacological and Toxicological Methods, v. 32, n. 2, p. 109-116, 1994.

16 LEWIS, A. J. V. C.; SPEER, D. G. Relationship between yield and composition of sow's milk and weight gains of nursing pigs. Journal of Animal Science, v. 47, n. 3, p. 635-638, 1978. 
18 SPINKA, M.; ILLMAN, G. B.; ALGERS, S. Z. The role of nursing frequency in milk production in domestic pigs. Journal of Animal Science, v. 75, p. 1223-1228, 1997.

19 LE DIVIDICH, J; .Et al Effect of fat content of colostrum on voluntary colostrum intake and fat utilization in newborn pigs Journal of Animal Science, v. 75, n. 3, p. 707-713, 1997.

20 RENADEAU, D.; NOBLET J. Effects of exposure to high ambient temperature and dietary protein level on sow milk production and performance of piglets. Journal Animal Science, v. 79, p. 1540-1548, 2001.

21 AULDIST, D. E.; Et al. The influence of suckling interval on milk production on sows. Journal of Animal Science, v. 78. 2026-2031, 2000.

22 FERREIRA, A. S. Estimativa da produção e composição de leite de porca e aleitamento artificial de leitões. Viçosa: UFV, 1986. 121 p.

23 VANDENBOOREN, J. C.; Et al. Comparison of blood glucose concentrations measured by enzymatic and reflectance photometric methods in fasting piglets Department of Herd Health and Ambulatory Clinic, Utrecht University, The Netherlands. Veterinary Research. v. 9, n. 3, p. 287-288, 1987.

24 LEPINE, A. J.; BOYD, R. D.; WHITEHEAD, D. M. Effect of colostrums intake on hepatic gluconeogenesis and fatty acid oxidation in the neonatal pig. Journal of Animal Science, v. 69, p. 1966-1974, 1991.

17 SAS INSTITUTE. SAS user's guide: statistics. versão 8.2. Cary, 2001. 